\title{
Conservadorismo e masculinidade tóxica na cultura gamer: Uma aproximação a Magic: The Gathering
}

\section{Conservatism and toxic masculinity in gamer culture: An approach to Magic: The Gathering}

\author{
THIA G O FA LC Ã Oa \\ Universidade Federal da Paraíba, Programa de Pós-Graduação em Comunicação. João Pessoa - PB, Brasil
}

TA RCÍZTO MA C E D O ${ }^{b}$

Universidade Federal do Rio Grande do Sul, Programa de Pós-Graduação em Comunicação. Porto Alegre - RS, Brasil

G A B RIELA KURTZ ${ }^{\mathrm{c}}$

Pontifícia Universidade Católica do Rio Grande do Sul, Programa de Pós-Graduação em

Comunicação Social. Porto Alegre - RS, Brasil

\section{RESUMO}

A partir de um esforço etnográfico empreendido entre os anos de 2016 e 2020, este artigo problematiza a encenação de uma masculinidade tóxica dentro de espaços de convívio relacionados ao card game Magic: The Gathering. O objetivo é sugerir uma relação entre os comportamentos observados e o reforço de valores conservadores na comunidade formada a partir da experiência deste jogo, avançando na compreensão das dinâmicas sociais da cultura gamer. Essa observação parte do pressuposto de que a comunidade de jogadores formada a partir da experiência desse jogo é o resultado da articulação de dois contextos sociotécnicos particulares: a cultura nerd e as mecânicas inscritas no design e na experiência do jogo em si. Palavras-chave: Masculinidade tóxica, conservadorismo, games, cultura nerd, Magic: The Gathering

\section{ABSTRACT}

Based on an ethnographic study conducted between 2016 and 2020, this article discusses the performance of toxic masculinity within social spaces related to the card game Magic: The Gathering. It suggests a relationship between the observed behaviors and the reinforcement of conservative values within the Magic community during the game experience, to further understand the social dynamics of gamer culture. Such observation stems from the assumption that the community of players formed during the game results from the articulation of two particular sociotechnical contexts: nerd culture and the mechanics inscribed in the design and experience of the game itself.

Keywords: Toxic masculinity, conservatism, games, nerd culture, Magic: The Gathering

${ }^{\text {a }}$ Professor Adjunto do Curso de Comunicação em Mídias Digitais da Universidade Federal da Paraíba e Coordenador do Programa de Pós-Graduação em Comunicação da UFPB. Orcid: https://orcid.org/0000-00016302-2264. E-mail: thiago. falcao@academico.ufpb.br

${ }^{b}$ Doutorando em Comunicação pela Universidade Federal do Rio Grande do Sul. Mestre em Comunicação, Cultura e Amazônia pela Universidade Federal do Pará, com período sanduíche na UFBA e Uneb. Orcid: https://orcid.org/00000003-3600-1497. E-mail: tarciziopmacedo@gmail.com

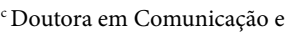
Informação na Universidade Federal do Rio Grande do Sul. Professora da Pontifícia Universidade Católica do Rio Grande do Sul. Orcid: https://orcid.org/0000-00028730-3383. E-mail: gabriela@ sidicom.com.br 


\section{INTRODUÇÃO}

DIMENSÃO POLÍTICA DO jogo é comumente negligenciada e esse fato possui duas raízes epistemológicas historicamente problemáticas. 1 A primeira delas diz respeito ao jogo em si e à reflexão em torno do fenômeno: o jogo, no senso comum, nunca foi considerado produtivo ou honrado; valoroso ou terreno. Sua condição sempre foi a de entretenimento pueril, devaneio, faz-de-conta, ficção, um impulso que deveria ser suprimido por sua inutilidade. Nunca foi o pilar para uma sociedade positiva ou compromissada com o desenvolvimento. Antítese de um paradigma funcionalista, mesmo sua condição pedagógica foi atenuada pelo fenômeno da midiatização (Hjarvard, 2013). Esta percepção remonta à Modernidade, no sentido latouriano do termo (Latour, 1993), considerando seu projeto civilizatório calcado na razão e na purificação dicotômica de fenômenos sociais complexos. Mesmo Huizinga (1938/2001) e Caillois (1958/2001), como aponta Trammel (2020), fugiram das dimensões mais obscuras da prática por estas não contemplarem sua epistemologia positiva e do lúdico como uma força social potencialmente boa.

A segunda raiz epistemológica desse problema se encontra na negligência genérica das dimensões materiais dos fenômenos sociais: como seria possível conceber os efeitos da ação técnica, ou de condições preexistentes resultantes de um sistema formal, quando os aspectos subjetivos sempre se sobressaem na discussão destes? A condição a partir da qual o sujeito encontra-se impreterivelmente em uma posição de superioridade para com o objeto impede que as dimensões materiais deste possam ser implicadas em um fenômeno qualquer seja como capacitantes, seja formadoras.

Para contemplar a dimensão política do jogo, há de se observar este a partir de outra episteme. O jogo enquanto ludus não é apenas "ação situada" - ele também é ação programada, prescrita. A ação desempenhada no jogo não é desprovida de sentido prévio, mesmo que possa ser transformadora. Ela acontece dentro de um contexto atipicamente circunscrito que orienta sua intencionalidade e prescreve sentidos.

Essa reflexão prévia orienta a argumentação deste trabalho ao conceber duas pedras fundamentais para seu desenvolvimento. Primeiro, que é necessário considerar o jogo como essencial para a compreensão de um tempo (Falcão, Marques \& Mussa, 2020), pois ele é uma força social tão significativa quanto, por exemplo, a política ou a religião, condição que foi sublinhada, sobretudo, nos trabalhos de Huizinga (1938/2001) e Caillois (1958/2001). Em seguida, que os objetos precisam ser considerados a partir de seus valores de associação, não de suas condições de subjetivação. Não importa apenas perceber o que o objeto conclama, do ponto de vista discursivo, mas sobretudo como essa condição 
pode ser percebida em suas materialidades. O jogo é fruto de seu tempo; sua estrutura, tributo a este.

Essa reflexão orienta a observação do contexto que se forma em torno do card game Magic: The Gathering (MtG), ou simplesmente Magic: uma abundante comunidade que movimenta jogadores profissionais e amadores, juízes, produtores de conteúdo, revendedores, fãs e toda sorte de papéis contemplados em âmbitos das indústrias criativas. A experiência nesse âmbito social ilustra (1) relações sociais e de poder importantes para a compreensão do espectro social contemporâneo, além de sublinhar o fato de (2) que essas relações podem ser percebidas não apenas na encenação de códigos culturais particulares, mas na materialidade de artefatos técnicos que prescrevem, por sua vez, formas de atuação a partir das quais indivíduos - jogadores - interagem.

Este artigo problematiza, assim, comportamentos de masculinidade tóxica performados dentro de espaços de convívio relacionados a Magic. A discussão se situa num imbricamento entre a relação histórica e cultural da masculinidade com a cultura dos videogames que mobiliza um tipo particular de encenação desta. Uma menos evidente e responsável por associar homens a conhecimentos e proficiência avançada em informática, enquanto parte de uma estrutura de masculinidade hegemônica ${ }^{1}$, conforme recuperaremos mais adiante.

Esta observação advém da articulação que a comunidade de jogadores de $M t G$ empreende a partir de dois contextos sociotécnicos: (1) a cultura nerd ${ }^{2}$, sobre a qual nos deteremos com mais afinco neste artigo, e (2) as mecânicas inscritas no design e na distribuição do jogo em si, dimensões que foram exploradas anteriormente (Falcão \& Marques, 2019), mas que retornam de forma tangencial na argumentação que se segue. Para além dessa discussão de ordem genealógica, esta pesquisa empreendeu uma incursão de ordem etnográfica tanto nos contextos físicos relacionados à prática de Magic, quanto nos contextos informacionais utilizados como suporte pelos atores aqui contemplados. Observamos, ao longo do ano de 2018, em três lojas físicas distintas localizadas no Nordeste do Brasil, um contexto interacional desenvolvido a partir da prática de $M t G^{3}$. Nesse contexto, percebemos duas condições que orientaram a análise desta comunidade de prática: primeiro, a escassez de mulheres jogadoras de $M t G$ em seu âmbito competitivo; depois, uma interdição nos discursos de problemáticas de gênero nos ambientes de jogo e circundantes a ele.

Em busca da compreensão desses âmbitos peculiares, monitoramos por todo ano de 2018 os grupos de WhatsApp relacionados a esses lugares particulares para buscar indícios que explicassem a ausência feminina nas competições em espaços físicos. Estas incursões nos permitiram compreender esses comportamentos e contextos sociotécnicos, apontando para relações de gênero e masculinidade
${ }^{1}$ A masculinidade hegemônica é aqui compreendida como um padrão de práticas que possibilitam o domínio dos homens sobre as mulheres (Connell \& Messerschmidt, 2005). As evidências indicam que as concepções ocidentais atuais de masculinidade são resultantes de uma história militar, social e econômica empreendida pelos estados capitalistas do Atlântico Norte (Connell, 1993). A masculinidade do jogador, portanto, emerge desses espaços ocidentais contemporâneos, por meio de uma crescente valorização do trabalho e do esforço, temas centrais para a criação da masculinidade hegemônica.

${ }^{2}$ Neste texto, nerd será definido como uma pessoa específica que detém interesse altamente técnico com dedicação obsessiva ou exclusiva em um assunto, especialmente tecnológico e/ou ligado a temas como fantasia, ficção científica, video games etc. A expressão, em parte como a conhecemos, foi cunhada em institutos politécnicos entre 1930 e 1940 e tem evoluído desde então, sendo dicionarizada por volta de 1979 graças ao papel crucial da televisão na popularidade e na disseminação da cultural nerd nos Estados Unidos, assim como na correlação com o termo geek (Lane, 2018).

${ }^{3}$ Parte importante dos dados de observação que compõem esta pesquisa também decorrem da participação em grupos institucionais pertencentes a esses espaços no aplicativo WhatsApp, utilizados pela comunidade por suas várias funções, que variam desde a manutenção da conversação em rede à estruturação das práticas de competição em MtG. 
tóxica em espaços voltados para o jogo e oferecendo um entendimento particular da manutenção desses espaços de repercussão ("câmaras de eco" e "espaços seguros") de discursos de cunho (ultra)conservador e reacionário (Braithwaite, 2016; Gray, 2014; Mortensen, 2018). Na seção a seguir, endereçamos uma breve incursão acerca do card game em que debruçamos nossa observação.

\section{UMA APROXIMAÇÃO A MAGIC: THE GATHERING}

Embora o jogo, em seu sentido amplo, seja um problema extensamente trabalhado dentro das ciências sociais e humanas, inclusive por pensadores emblemáticos desses campos (Goffman, 1961; Simmel, 1983, dentre outros), discutir jogos em seu sentido estrito e as relações sociais estabelecidas a partir deles ainda é um desafio, sobretudo em contextos limítrofes e de interdisciplinaridade. Se discutimos esportes - um tipo particular de jogo organizado e aceito socialmente -, o problema é dissipado pelo conhecimento latente oriundo do convívio cultural acerca das regras do futebol, vôlei ou mesmo da excentricidade de alguns esportes olímpicos. Quando nos debruçamos sobre o video game ou mesmo sobre a crescente cultura dos jogos de tabuleiro, o problema se adensa: como podemos compreender aspectos internos de uma cultura se não entendemos os aspectos técnicos que a guiam? Cada uma dessas culturas voltadas para os videogames, em suas muitas representações contemporâneas, é impulsionada, antes de tudo, pelos aspectos do design inscritos em cada um destes contextos técnicos particulares (Falcão, 2014).

Magic, jogo a partir do qual se organiza o contexto social por nós observado, é extenso e complexo em suas regras, formatos competitivos e, mais importante, nos contextos sociais que o cercam. Criado por Richard Garfield - matemático, inventor e game designer americano -, MtG foi o primeiro trading card game (TCG) moderno a ser criado e não é apenas um simples jogo de cartas. A forma mais justa de descrevê-lo, e um dos clichês utilizados pela comunidade, reside

No original: "it's like chess and poker at the same time". Esta e demais traduções, dos autores. na seguinte acepção: "é como xadrez e pôquer ao mesmo tempo"4 (Morris-Lent, 2015). Sua estrutura funciona de acordo com a combinação de cartas para um propósito final: a vitória. O TCG é jogado em seu formato competitivo por dois jogadores em uma batalha que combina a expertise e as regras - uma perícia mental, agonística - com a sorte de comprar cartas ideais no timing correto - no que é percebido como aleatoriedade. Diferentemente do xadrez ou do pôquer, que possuem conjuntos limitados de peças - nas 32 peças do xadrez ou nas 52 cartas de um baralho -, desde 1993, Magic vem contando com adições ao seu conjunto de peças, que neste caso são cartas que podem ser combinadas com outras para efeitos específicos. 
Dois aspectos básicos fazem Magic diferir de jogos de carta tradicionais que fazem uso de baralhos: o primeiro deles é o fato de que subsiste um aspecto diegético forte em sua concepção, o qual está intrinsecamente ligado à forma como o jogo é codificado pelo time de game design na Wizards of the Coast, empresa responsável por sua publicação. Magic simula um duelo entre dois planeswalkers (ou "andarilhos de planos", em tradução livre). No argumento que serve de base ficcional para o jogo, inúmeros planos de existência ocupam um multiverso. Se esta dimensão narrativa parece irrelevante, ela não o é: os personagens e os mundos criados pela Wizards of the Coast são a principal ferramenta para que sejam elaboradas estratégias de publicidade e de midiatização do público em mídias sociais (Švelch, 2020).

A estrutura que permite a competição, por sua vez, é o outro fator que diferencia Magic de outros jogos clássicos de cartas: um jogador precisa, para jogar, de um deck, uma coleção de 60 cartas que serão usadas na partida. Essas cartas são organizadas previamente a partir de uma estratégia de jogo particular e podem ser oriundas de qualquer uma das dezenas de expansões do jogo. $\mathrm{O}$ aspecto variável da estrutura do jogo é interessante, do ponto de vista do design: Magic se torna, a partir dele, um jogo de emergência (Juul, 2005) muito particular, que orienta seu aparato a partir de um plano de jogo, mas que depende da compra as cartas necessárias em um movimento de quase aleatoriedade ${ }^{5}$. É necessário, portanto, fazer julgamentos com base no que se espera tanto do adversário, quanto do seu próprio deck e, finalmente, contar com a sorte, para suceder.

Por fim, para encerrar esta digressão e retornar à discussão central sobre comportamentos identificados a partir de suas comunidades de prática, é necessário sublinhar que o acesso a essas cartas não é particularmente equânime: Magic é comercializado em booster packs - pacotes que contêm cartas organizadas a partir de sua raridade - e cada booster possui quinze cartas, das quais apenas uma é de raridade rara ou mítica. Essa relação afeta a frequência com que uma carta pode aparecer e também impacta a qualidade de uma carta em seu design: cartas raras costumam ser mais poderosas e versáteis, desequilibrando comumente o jogo em seu favor, a partir de seu valor absoluto.

A raridade das cartas é um fator mais relevante do que se pode imaginar à primeira vista, uma vez que um jogador só pode adquirir uma carta de duas formas: ou ele compra um booster e conta com a sorte de vir a carta desejada, uma probabilidade consideravelmente baixa, ou ele compra a carta de lojas especializadas que revendem cartas específicas - chamadas de singles -, em uma prática que a comunidade nomeia de "mercado secundário". A depender dos fatores raridade e demanda, considerando sua importância em dado momento, 0 preço de uma carta pode variar de algumas dezenas a algumas centenas de reais.
${ }^{5}$ Um tutorial sobre como jogar $M t G$ foi disponibilizado em: Wizards of the Coast (2017) 


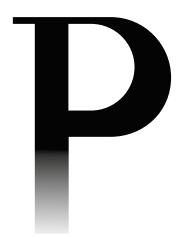

${ }^{6} \mathrm{~A}$ expressão inglesa geek, com uma conotação similar à que testemunhamos hoje, surgiu no ano de 1980 e se popularizou na década seguinte, sendo utilizada de maneira correlacionada com o termo nerd. Para Lane (2018), o termo geek tem sido utilizado em substituição ao antigo nerd no uso comum. Há uma outra percepção que associa nerd a tecnólogo e geek a fã e consumidor de cultura pop, como um entusiasta e moderno, enquanto os nerds estariam relacionados a pessoas mais intelectuais.

${ }^{7}$ Recentemente, a literatura especializada tem argumentado que os termos nerd e geek não são de simples definição, principalmente quando se consideram as complexidades do uso cotidiano (Lane, 2018).

A despeito das diferenças, optamos pelo emprego do termo nerd na ampla maioria dos casos, compreendendo-o como equivalente semântico de geek, tanto porque ambos são enquadrados como jogadores a partir da tecnocultura, quanto a partir do natural e intrínseco intercâmbio entre as ideias-chave das expressões - a obsessão devotada a uma determinada busca, inteligência, tecnologia e gênero masculino, por exemplo (Lane, 2018).

${ }^{8}$ Como discutido no artigo de Chase (2018).

${ }^{9}$ As plataformas são usualmente utilizadas como subsídio para treino ou experimentação, ao passo que as competições locais são percebidas de forma mais natural como de maior importância, uma vez que são sancionadas - ou seja, reconhecidas - pela Wizards of the Coast.
Assim, percebemos que existe, no próprio design do jogo, um direcionamento a públicos de jogadores muito específicos. Uma breve consulta a um site dedicado a $M t G$ mostra, no momento em que este artigo é escrito, decks baratos na faixa de 290 dólares (Griffith, 2020) e decks particularmente caros na faixa de 1400 dólares (Zeranox, 2020). A demografia principal de Magic é constituída por pessoas que integram a chamada cultura geek ${ }^{6} /$ nerd $^{7}$, que tende a ser masculina, branca, classe média e cis-heterossexual (Salter, 2018; Salter \& Blodgett, 2017). Em sua obra sobre raça, gênero e desvio em videogames, Gray (2014) afirma que uma observação da masculinidade retratada nos e pelos videogames precisa ser compreendida a partir de variadas lentes. Na próxima seção, evocamos uma discussão histórica sobre a construção de masculinidades na cultura nerd e o modo como este aspecto se imbrica com o contexto dos videogames, no geral, e de $M t G$ em particular.

Em tempo, uma consideração é importante para enquadrar o trabalho que aqui se apresenta, no que diz respeito às formas de experimentação de Magic. A questão que se enseja endereça uma incongruência percebida no fato de que este artigo discute a toxicidade da cultura gamer, ainda que não se reconheça Magic necessariamente como um videogame, mas sim um TCG. Um ponto aqui deve ser levado em consideração: os atravessamentos técnicos e simbólicos percebidos por Švelch (2020) em sua discussão acerca do processo de midiatização sofrido por Magic. Fato é que o ecossistema no qual a prática deste jogo se desenrola é um continuum composto por uma dimensão física, presencial, e uma dimensão midiatizada, plataformizada.

É, em nossa opinião, metodologicamente infrutífero explorar essa distinção: a etnografia realizada apontou um atravessamento absoluto entre o espaço físico das local game stores (LGS) e a experiência das plataformas nas quais se pode experimentar o jogo. Esta condição, combinada com o fato de que a própria Wizards of the Coast assumiu publicamente que estava elevando Magic à categoria de esport ${ }^{8}$, em nossa percepção, é mais que suficiente para que a distinção TCG/plataforma seja vista como apenas uma tecnicalidade que não se sustenta na observação do cotidiano dessa comunidade ${ }^{9}$. Isso denota que nossa aproximação ao jogo deve se direcionar não à plataforma em específico, mas a toda infraestrutura, que é precisamente o trabalho empreendido nesta etnografia. Isso implica, também, que é possível notar nessas relações nuances provenientes de quaisquer contextos percebidos - o que nos leva a constatar construções de masculinidade e toxicidade como oriundas tanto da cultura nerd quanto da cultura gamer. 


\section{CULTURA NERD E A CONSTRUÇÃO DE MASCULINIDADES}

A confluência de forças sociais que impulsionou as transformações culturais das décadas de 1960 e 1970 foi crucial para o desenvolvimento da cultura dos videogames (Robinson, 2007). Movimentos sociais multiculturalistas como a contracultura, por exemplo, ofereceram condições para que as transformações na tecnologia fossem ampla e gradativamente aceitas e se estruturassem em um padrão ao qual, dado tempo, se estabeleceriam no âmbito sociotécnico da cibercultura (Salter, 2018). Essas condições culturais também eram apropriadas em outras esferas mais específicas e na ordem de um nicho cultural, nas quais se experimentava uma segmentação peculiar orientada a jovens brancos de classe média, prioritariamente do sexo masculino, com faixa etária entre 18 e 25 anos e cursando o ensino superior (Robinson, 2007).

Compreender esse contexto é fundamental para construir uma percepção crítica da cultura nerd que seja intrinsecamente conectada com o reconhecimento que a habilidade tecnológica conquistou na vida social (Salter, 2018). O surgimento dessa identidade, em particular, provocou uma crescente problematização das bases nas quais ela se fundamenta (Kendall, 1999, 2000): West e Fenstermaker (1995) apontam, a partir da ideia de que todas as relações sociais são orientadas pelo gênero, racializadas e classistas, que a origem da cultura nerd está fortemente atrelada aos ideais de masculinidade hegemônica ocidentais, mais especificamente estadunidenses.

É reconhecido que, ao longo das linhas temporais e geográficas, as masculinidades se transformam e são traduzidas de distintas formas, dependendo do local e de diversas outras tensões existentes na sociedade (Connell \& Messerschmidt, 2005; Reeser, 2010). O potencial de uma nova forma de masculinidade, a qualquer instante, ser exaltada culturalmente sobre outras formas hegemônicas preexistentes (Connell, 2001) torna o cenário ainda mais delicado.

Para Chandler (2019), a masculinidade hegemônica - isto é, em termos de poder - é uma abordagem predominante nos estudos da masculinidade. $\mathrm{O}$ alicerce da masculinidade hegemônica se encontra em um entendimento da existência feminina como potencial validação sexual para os homens, ao passo que estes competem entre si com o intuito de conquistar esse "objeto sexual" (Gray, 2014). Gray reitera que a masculinidade hegemônica consiste em um padrão de práticas que situam as mulheres em um estado contínuo de submissão. Chandler (2019), por sua vez, refere-se à masculinidade hegemônica a partir do que crê ser sua nomenclatura atualizada no termo masculinidade tóxica, pois este convoca uma percepção da construção das identidades masculinas com relação à sua toxicidade (Chandler, 2019; Kupers, 2005). 
${ }^{10}$ Ainda que recentemente tanto a indústria AAA de videogames quanto as produtoras independentes venham explorando temáticas multiculturalistas e inclusivas, além de desafiar construções acerca dos conceitos de masculinidade e feminilidade, esses jogos representam apenas uma parcela pequena do output da indústria como um todo. Para além desta consideração, subsiste também o fato de que este movimento pode ser percebido como uma estratégia de precorporação (Fisher, 2009), na qual a indústria se apropria de conteúdos ideológicos não por corroborá-los, mas por seu potencial comercial.
A partir dessa aproximação, as definições anteriores servem igualmente de apoio a uma compreensão das masculinidades tóxicas como traços masculinos socialmente regressivos que servem para nutrir a dominação, a desvalorização da mulher, a homofobia e a violência (Kupers, 2005). Essa compreensão objetivada e expropriada da feminilidade caracteriza a masculinidade tóxica (Chandler, 2019), que, na cultura dos videogames, é concebida como predominante e a partir da qual a comunidade costuma ser frequentemente estigmatizada pela forte correspondência com traços como homofobia, misoginia, racismo e tendência a comportamentos hostis e violentos, expressões da masculinidade tóxica.

Considerando esta discussão e o contexto cultural documentado em vários trabalhos do campo dos game studies (Chandler, 2019; Massanari, 2017; Salter, 2018; Salter \& Blodgett, 2017), a performance da masculinidade nos videogames tem relação estreita com a masculinidade nerd - e esta se relaciona intimamente com o domínio tecnológico no ambiente do jogo. Em sua concepção, a cultura dos videogames foi orientada pela promoção de uma masculinidade militarizada, por meio de variadas práticas de design de jogos e narrativas centradas em cenários de guerra (Johnson, 2018).

Além disso, a própria estrutura do mercado dos videogames inviabiliza e torna arriscado o desenvolvimento de jogos inclusivos que proponham uma reordenação das percepções de feminilidade e da mulher ${ }^{10}$. Um fator preponderante para isso é o entendimento convencional da identidade de jogador como sendo associada a uma demografia específica - homem, branco, cisgênero, heterossexual e de classe média (Gray, 2014; Johnson, 2018; Murray, 2018; Robinson, 2007; Salter \& Blodgett, 2017) -, cuja representação é parte fundamental das estruturas de poder moldadas na cultura dos videogames por décadas (Braithwaite, 2016). Com a ascensão da tecnologia digital - e da cultura relacionada a ela - a partir dos anos 1980, sobretudo no contexto da cultura norte-americana, ser nerd também passou a significar aptidão e inteligência em ramos que negociam com o conhecimento tecnológico. Nesse contexto, a imagem do nerd também passa a gozar de maior aceitação, dadas as profundas sobreposições sociotécnicas e crescente valorização da tecnologia (Salter \& Blodgett, 2017).

A masculinidade nerd é mais visível no instante em que os membros dessa cultura se consideram sitiados por algum produto ou ação, geralmente de cunho multiculturalista, que costumam provocar uma articulação nos fóruns e comunidades que abrigam e fomentam a identidade nerd, fazendo com que os membros se manifestem repudiando em massa a origem da mágoa (Salter \& Blodgett, 2017). A estratégia desses sujeitos consiste em constituir um lobby em fóruns e serviços de redes sociais com o objetivo de inviabilizar qualquer discurso a favor da diversidade e do multiculturalismo. Eles compõem o que 
Massanari (2017) chama de tecnoculturas tóxicas, conceito utilizado para "descrever as culturas tóxicas que são ativadas e propagadas por redes sociotécnicas como Reddit, 4chan, Twitter e jogos on-line"11 (p. 333).

A relação entre essa identidade nerd e as hierarquias culturais estabelecidas, o que incorpora a masculinidade hegemônica, interrompe a promoção de uma reconciliação pelo nerdom (grupo de nerds) ante sua posição no contexto da cultura pop contemporânea. O modelo arquetípico do nerd hipermasculino ${ }^{12}-$ uma identidade construída pela rejeição tanto da cultura e das construções femininas, quanto da estética masculina atlética tradicional (Salter \& Blodgett, 2017) - esboça tão somente a substituição de um ideal tradicional hipermasculino ${ }^{13}$ por outro padrão que permanece atuando na manutenção da masculinidade hegemônica no âmbito da cultura pop.

Nesse sentido, embora o fato do nerd ter conquistado relevância como ícone cultural represente significativa mudança (Salter \& Blodgett, 2017), esse aspecto não deixa de operar na conservação da posição dominante dos homens e da subordinação das mulheres (Connell, 2005). Ainda que exista um movimento para maior diversidade nas produções midiáticas nesse contexto, a ideia na qual a figura do nerd foi construída e o homem branco cis-heterossexual que a representa parecem dificultar a inclusão e participação feminina em conteúdos, ações e comunidades de prática dessa cultura.

A noção de boyhood, de Burrill (2008), é particularmente profícua para ilustrar nosso ponto: ela propõe uma natureza regressiva da masculinidade no contexto capitalista de primeiro mundo, onde pressões externas acabam por forçar o homem à infância masculina. Burrill sublinha que os jogos seriam a ferramenta ideal para essa manifestação nos ambientes digitais, pois servem como espaços de regressão, permitindo a fuga, a fantasia, um ambiente longe do feminismo - e do feminino não idealizado -, da luta de classes e de responsabilidades familiares e políticas. Neste escape onde o homem pode tentar provar-se masculino, é de se esperar, portanto, que as tentativas de invasão constituam ameaças, transportando para esses invólucros questões do dito mundo real. Esses movimentos na cultura nerd são responsáveis pela manutenção de um suposto desejo de salvar o passado (Salter \& Blodgett, 2017), sob a premissa de que este lhes proporcionou mais benefícios do que o presente.

As ações incluem, por exemplo, agir para manter a ficção científica sem pretensas agendas políticas e metáforas sociais, atuar na proteção de videogames hipermasculinos da interferência feminista e, em síntese, preservar espaços culturais nerds para os verdadeiros participantes que partilham dessa experiência, dessa identidade e desse mesmo conjunto de valores, sem jamais testá-los ou desafiá-los (Salter \& Blodgett, 2017). Esse argumento convoca uma dimensão

\author{
${ }^{11}$ No original: "describe the \\ toxic cultures that are enabled \\ by and propagated through \\ sociotechnical networks such \\ as Reddit, 4 chan, Twitter, and \\ online gaming". \\ ${ }^{12}$ Refere-se a um modelo \\ derivado das visões duais \\ que representam os nerds ora \\ como vítimas, ora como heróis \\ outsiders - em decorrência da \\ redefinição da masculinidade \\ ou do contexto (Salter, 2018; \\ Salter \& Blodgett, 2017). Na \\ cultura visual dos Estados \\ Unidos, há uma forte tendência \\ ideológica que caracteriza \\ a brancura - e de maneira \\ especial o protagonista \\ masculino branco - como uma \\ vítima e não um como herói \\ (Murray, 2018). \\ ${ }^{13} \mathrm{O}$ ideal hipermasculino é \\ tradicionalmente representado \\ pela aptidão física, interesse por \\ esportes e cerveja e uma total \\ aversão pelo domínio intelectual \\ (Salter \& Blodgett, 2017).
}


${ }^{14}$ Robin (2011) posiciona o conservadorismo como uma ideologia de reação, originalmente contra a Revolução Francesa e, mais recentemente, contra os movimentos de libertação dos anos 1960-1970.

${ }^{15}$ No original: "to delight in what is present rather than what was or what may be".

${ }^{16}$ No original: "mode of counterrevolutionary practice". nostálgica que detém um papel fundamental na construção da identidade nerd e do jogador, assim como revela uma aproximação com uma disposição conservadora (Oakeshott, 1991) ao extremo, responsável por tingir, discursivamente, um determinado período com ideias embelezadoras, românticas e árcades. $\mathrm{O}$ tópico a seguir concentra-se em problematizar essas marcas do passado e a ideologia que elas acionam no contexto cultural que observamos.

\section{O CONSERVADORISMO COMO OPERADOR NA CULTURA NERD/GAMER}

A cultura nerd/gamer incorpora um relacionamento tênue com o passado: a evocação de um desejo nostálgico por um período histórico que não foi tão idílico ou descomplicado quanto o imaginário desta cultura o concebe (Salter \& Blodgett, 2017); um certo sentimento de gratidão dirigido a um passado que supostamente teria legado bases fundamentais e necessárias de conservação no presente. A nostalgia, neste caso, é uma influente força cultural e emocional repetidamente utilizada para defender uma ideologia conservadora ${ }^{14}$, revelando o passado como um ideal inacessível em comparação com a realidade do presente (Coontz, 2000).

Oakeshott (1991), um dos principais filósofos do pensamento conservador, concebe o conservadorismo como uma disposição. Isto significa que o ânimo por se satisfazer com o que está colocado à disposição no presente, aliado à rejeição pelo desejo ou pela busca por algo novo no futuro, ainda indefinido, seriam as bases do conservadorismo: "deleitar-se com o que está presente, em vez do que foi ou pode $\operatorname{ser}^{\prime 15}$ (p. 1). Sua visão, portanto, reforça um pensamento conservador afirmativo do presente. Ainda assim, o autor reconhece que o conservadorismo é, geralmente, justificado na iminência do sentimento de perda, "na ideia de que aquilo que o presente lhe oferece está prestes a ser ceifado por alguma agenda política radical" (Trigueiro, 2015, p. 102).

Trigueiro (2015) reforça a necessidade de relativizar o conceito de Oakeshott (1991), na medida em que as ideias de presente e passado estão, por definição, conectadas. Se Oakeshott (1991) oferece uma leitura do conservadorismo do ponto de vista de um intelectual que é ele mesmo conservador, por outro lado, é relevante problematizá-la com uma compreensão do fenômeno dada por um pensador cuja orientação política é diametralmente divergente: Robin (2011). Este autor define o conservadorismo como uma meditação - e uma interpretação teórica - acerca da experiência de deter o poder, tê-lo ameaçado e tentar recuperá-lo, ou apenas atuar na sua manutenção.

Robin (2011) situa as ideias conservadoras como um "modo de prática contrarrevolucionário"16 (p. 17) que emerge para preservar os privilégios, as 
hierarquias e o poder de alguns sobre outros, na esteira de um movimento democrático. Essa abordagem crítica é distinta da definição de Oakeshott (1991), cujas bases são construídas em torno de temas como liberdade, governo limitado, resistência à mudança e à inovação como condição da natureza e do caráter humano - o qual defende ser refratário a essas bruscas iniciativas - ou virtude pública.

Em outros termos, a ideologia conservadora pode ser compreendida como uma reação determinada, uma defesa aos ataques de um movimento específico de emancipação, que no decorrer da condução de sua resposta também costuma fagocitar consistentemente traços do movimento a que se opõe (Robin, 2011). Na chamada "Era Moderna" esse tom cético e de preocupação com a preservação de privilégios dos conservadores, diante das possibilidades de dobras radicais nas estruturas de poder e hierarquia da sociedade, são mais frequentes na esfera privada que na pública, encontrando lutas contra causas como os movimentos trabalhistas e o feminismo (Robin, 2011) ${ }^{17}$.

$\mathrm{O}$ argumento de Robin (2011) reforça que subsiste perenemente um ânimo classista na retórica conservadora, ou seja, de que esta guarda uma ideia de interdição, em distintos níveis, acerca da liberdade e agência das classes subalternas. O autor desenvolve uma crítica que entende o conservadorismo como reativo e contingente a uma agenda e a um programa político radical antagônicos - sem os quais perde força e potência retórica -, além de ser complementar à esquerda. Essas ideias políticas - que recebem nomes de conservadoras, reacionárias, revanchistas ou contrarrevolucionárias - tiveram origem e cresceram, segundo Robin, justamente em batalhas e na polarização. Da Revolução Francesa às lutas pela liberdade negra, dos movimentos de descolonização às lutas dos povos e comunidades tradicionais, da revolução sexual até a liberação feminina, a mudança de ameaça transforma as formas de combatê-la (Robin, 2011).

Retomando o olhar ao contexto da cultura nerd e dos videogames, os membros dessas comunidades procuram frequentemente afirmar sua cis-heteronormatividade e seus papéis hegemônicos de gênero sob o disfarce de uma perspectiva nostálgica conservadora que denota um vitimismo ilusório. Da mesma forma, a campanha de abuso on-line conhecida como Gamergate ${ }^{18}$ também teve seu discurso alimentado pela nostalgia e revelou uma manifestação sociotécnica coerente entre masculinidades nerds e formas de abuso, assédio, ataque e constrangimento on-line impulsionados por diversas plataformas digitais, como Twitter e Reddit (Massanari, 2017; Salter, 2018). Os gamergaters - como assim ficaram conhecidos - disciplinaram e difamaram os críticos, seguros da premissa de que eles necessitavam ser reinseridos em seu lugar: subalternizá-los é o caminho, defenderam. A retórica do movimento sugere a existência de
${ }^{17}$ Sublinhe-se que, historicamente, a comunidade nerd/gamer concebe seus espaços muito mais sobre um âmbito privado do que propriamente público, dadas as suas condições de acesso.

${ }^{18}$ Foi uma campanha misógina originada no contexto da indústria dos videogames e nas comunidades de jogadores em agosto de 2014, após o desenvolvedor de jogos Eron Gjoni divulgar um artigo difamatório de sua ex-companheira, a também desenvolvedora Zoe Quinn. A ação foi uma retaliação depois do término do breve relacionamento entre ambos (Salter, 2018). Os chamados gamergaters situam o homem branco cis-heterossexual como o jogador típico e as verdadeiras vítimas do Gamergate, oprimidos pelos constantes pedidos de diversidade e correndo o perigo de perder seus jogos para outros com teor mais inclusivo (Braithwaite, 2016). 
${ }^{19}$ No original: "Nostalgia for a safer, more placid past fosters historical amnesia about these precedents, deforming our understanding of what is and is not new".

${ }^{20}$ No original: "If the 1950 s family existed today ... we would not have the contemporary social dilemmas that cause such debate".

${ }^{21}$ No original: "a seemingly gender-neutral indictment of family irresponsibility ends up being directed most forcefully against women". uma cruzada contra feministas e outros inimigos eleitos, muitas vezes direcionando ataques misóginos, antissemitas, racistas, homofóbicos e transfóbicos (Braithwaite, 2016; Salter, 2018).

A cultura nerd, e por sua vez a cultura gamer, são partidárias de um comportamento nostálgico fortemente relacionado com uma disposição conservadora (Oakeshott, 1991) extremista ou espírito (ultra)conservador, como sugerido por Coontz (2000). O argumento da autora se debruça sobre o quanto o ideal do passado se mostra como um veículo para ideologias reacionárias, incluindo aquelas preocupadas com papéis de gênero que tentam problematizar a sociedade em seu estado corrente por não se manter de acordo com padrões do passado (Coontz, 2000). "A nostalgia por um passado mais seguro e plácido promove uma amnésia histórica sobre antecedentes, deformando nossa compreensão do que é e do que não é novo" ${ }^{19}$ (p. 12). Parte da retórica de nerds e de jogadores de $M t G$ fundamenta-se em uma perspectiva centrada no passado do gênero masculino, num movimento dedicado à manutenção de uma estrutura de privilégios, papéis sociais hegemônicos, cis-heteronormativos e misóginos.

Em seu estudo, Coontz (2000) analisa a tendência da sociedade contemporânea, especialmente no contexto norte-americano, de enquadrar os anos 1950 como a representação de um período histórico em que a família era saudável e, por conseguinte, ideal. Essa época se tornou um marco para muitos como uma idade de ouro próspera na vida familiar tradicional. Uma profunda nostalgia cultural e emocional por esse passado inventado se construiu, independentemente desse constructo perfeito ser efetivamente alcançável em qualquer ponto da história. O argumento evocado recorrentemente é o de que "se a família dos anos 1950 existisse hoje . . . não teríamos os dilemas sociais contemporâneos que provocam tal debate"20 (p. 46).

Coontz sugere que esse discurso implica um regresso aos valores familiares de outrora, o que encoraja a moralização e o pensamento ideológico hegemônico conservador: "uma acusação aparentemente neutra em gênero de irresponsabilidade familiar acaba sendo dirigida com mais força contra as mulheres"21 (p. 60), culpando-as pela crise da família tradicional a partir da transformação de seus papéis na sociedade. A insistência em um "retorno à família tradicional" dá suporte para que as representações de gênero e sexualidade dentro da cultura nerd/gamer - e a retórica nostálgica adotada pelos seus membros - reafirmem a dinâmica de poder dominante com intuito de resgatar os privilégios de um passado supostamente superior a um presente posto como degenerado e em decadência.

Em Magic, os jogadores evocam um tipo-ideal do passado a partir de uma dimensão nostálgica de identidade, como já dito, estruturante dos tecidos intersubjetivos da cultura nerd. Assim como facções do espectro político conservador 
e de extrema direita do Brasil e dos Estados Unidos anseiam pela perfeita vida doméstica da era do pós-guerra, no auge dos alcunhados anos dourados da década de 1950 (Coontz, 2000)22, os jogadores olham para uma lendária era de ouro do nerdom. Esse período nunca existiu para além do imaginário ou da falsa sensação passada, na necessidade contínua de garantir a proteção, o privilégio, $\mathrm{o}$ poder, a exclusividade masculina e o controle da tecnologia por certos espaços e atividades nerds (Salter, 2018).

A infelicidade dos jogadores decorre de descobrirem que a nostalgia é mais potente que a realidade. Essa constatação leva a uma procura para definir internamente o que contribuiu para o contexto infeliz experimentado hoje. Sua tristeza deve pertencer a algum lugar e a caça por culpados esbarra, sobretudo, nas feministas, que são recorrentemente associadas - na mídia, nas inúmeras plataformas disponíveis na internet ou na própria vida cotidiana ${ }^{23}$ - a um discurso de infelicidade e raiva, em oposição às alegres e submissas esposas conservadoras. A felicidade assume, então, uma retórica que a concebe como um bem emocional e econômico proveniente exclusivamente dos lares de classe média (Ahmed, 2010). "As feministas nem precisam dizer nada para serem lidas como estraga-prazeres ... elas perturbam a própria fantasia de que a felicidade pode ser encontrada em certos lugares"24 (Ahmed, 2010, pp. 65-66).

Apoiada na filosofia e nos estudos culturais feministas, Ahmed (2010) endereça uma provocativa análise crítica cultural do imperativo de ser feliz. A autora demonstra com precisão o quanto a felicidade é utilizada historicamente como um modo de justificar a submissão e opressão social, sustentado por meio de diversas técnicas de violência e subjugação em prol da manutenção de um pacto social que privilegia o direito de alguns sobre outros (Ahmed, 2010). Sua abordagem também revela como a opressão desafiadora causa infelicidade, $o$ trabalho afetivo e moral desempenhado pelo "dever da felicidade" e o quanto ela é assim prometida para apenas aqueles que desejam viver suas vidas da "maneira certa" - aquela que é socialmente validada.

Assim, feministas e outros grupos críticos são alvos fáceis da frustração dos jogadores com suas comunidades e vidas. Se a valorização acrítica e política das diferentes mídias, produtos e derivados nerds é recorrentemente considerada na atmosfera desta cultura, feministas ou qualquer outro sujeito distinto passam a ser encarados como vilões (Salter \& Blodgett, 2017). Partindo de um pensamento similar de Salter e Blodgett (2017), podemos sugerir que pensar em mulheres e grupos minoritários como integrantes dessas comunidades rompe a imagem do jogador como um homem solitário e antipático. Qualquer tentativa de ruptura dessa atmosfera compartilhada, e de uma visão desses sujeitos como visivelmente diferentes, gera atos manifestos de masculinidade tóxica.
${ }^{22}$ Com o consequente retorno da família tradicional e, no contexto nacional, dos momentos áureos que creem ter vivido durante a ditadura civil-militar brasileira.

${ }^{23}$ Como se pode contemplar, por exemplo, em vídeos produzidos pela youtuber Bruna Torlay (2020).

${ }^{24}$ No original: "Feminists don't even have to say anything to be read as killing joy ... they disturb the very fantasy that happiness can be found in certain places". 
${ }^{25}$ No original: "For some players, there is a genuine sense of loss, watching games becoming mainstream and accessible".
Nesse sentido, o sentimento de nostalgia dos jogadores também destaca dois aspectos fundamentais desta cultura: (1) os laços estreitos entre o jogador e uma identidade de gênero masculina; (2) e o jogador como uma categoria de consumidor que tem seu esforço considerável de tempo limado com uma crescente popularidade e acesso dos jogos hoje: "Para alguns jogadores, há um sentimento genuíno de perda, vendo os jogos se tornarem populares e acessíveis" ${ }^{25}$ (Juul, 2010, p. 151). Da mesma forma como encenado no Gamergate (Braithwaite, 2016), esse sentimento de perda está relacionado à masculinidade gamer, a tal ponto que a abertura para novos grupos é vista como um ataque aos homens e à identidade de seus "membros originários”. Há aqui uma percepção que aproxima este comportamento, como dito, de um certo etos romântico próprio da disposição conservadora, a qual, usualmente, posiciona-se como uma voz que reclama pela ameaça de perda de poder.

Novamente, o uso da identidade como arma é central nas estratégias retóricas e campanhas de ódio voltadas para o público feminino, como observado no caso Gamergate documentado dentro da vasta agenda de pesquisa acerca do tema (Braithwaite, 2016; Salter \& Blodgett, 2017). O artifício nostálgico evocado também recupera um entendimento do sofrimento como parte do que tornaria os gamers excludentes, sendo, assim, acionado para lhes oferecer certa superioridade moral e justificar suas reivindicações agressivas e misóginas como uma forma de defesa que disfarça, em verdade, o ódio oculto em uma campanha de apelo moralizante contra uma certa ameaça a seu espaço de domínio (Braithwaite, 2016). Essa postura de vitimização procura enevoar relações de dominação mantidas por meio do controle e afirmação do poder tecnológico (Salter, 2018). Essa forma de poder é manifesta em competições por status e respeito que se impõem entre e sobre outros homens, das quais o sexo feminino é reiteradamente excluído, recorda Salter (2018). Adensaremos essas e outras questões no tópico que se segue.

\section{ANÁlISE E DISCUSSÃO}

Considerando o que foi dito até agora, é necessário que nos debrucemos sobre a prática local de Magic a fim de observar o movimento de produção e encenação de masculinidades tóxicas. Essa aproximação possui uma sensibilidade antropológica e inspiração etnográfica e combina o convívio e a entrada cultural empreendidos nos lugares de consumo e proliferação do jogo, com a observação de comunidades-suporte no aplicativo de WhatsApp. Tal composição metodológica busca uma observação mais completa das interações e utiliza os aparatos digitais para ilustrar o fenômeno de forma adequada. 
A questão que se sobressai nessa decisão diz respeito ao fato de que o comportamento observado nas LGS, por si só, não é suficiente para descrever de que forma esses lugares dão vazão a comportamentos tóxicos ou reacionários: nossa observação indica que a performance localizada é, muitas vezes, o culminar de uma relação mantida a partir dessas outras plataformas ${ }^{26}$. No caso de LGS que movimentam cenas muito particulares, envolvendo um número limitado de jogadores - em detrimento de eventos como um grand prix (GP) ou um campeonato de porte maior -, o convívio é comunitário e pessoal. Os grupos de WhatsApp, sobretudo, funcionam como uma extensão do espaço físico da loja na qual é possível estabelecer relações por causa do/com o jogo. Essas comunidades são comumente utilizadas para manter os atores envolvidos, tanto na dimensão do jogo - dando vazão à discussão acerca de aspectos técnicos, na repercussão na mídia ou mesmo em lançamentos comerciais -, quanto em um convívio mais amplo, orientado por valores compartilhados pelos diversos grupos nelas representados.

Assim, é impreterível que nos debrucemos sobre essas plataformas, porque em última instância muitos dos comportamentos situados são contextualizados ou justificados pela construção de relações nessa dimensão, o que fortalece a continuidade da experiência social, em detrimento da percepção de que fóruns, serviços de redes sociais e outros dispositivos digitais promovem uma comunicação efêmera ${ }^{27}$. Esse conjunto de dispositivos adicionais fornece, desta forma, subsídios para que os jogadores se componham de maneira permanente nas redes de jogos. Os dispositivos digitais que dão suporte à continuidade da experiência comunal do jogo facilitam, por sua vez, a conversação em torno de outros temas. Memes, conteúdos jornalísticos e políticos circulam com considerável facilidade, provocando ânimos e compelindo certos comportamentos.

Protegidos pela impressão de anonimato e por aquilo que Gray (2014) chama de desinibição on-line tóxica, indivíduos particularmente silenciosos em interações pessoais nas lojas se mostram defensores eloquentes de suas ideias, o que sugere que as interações sociais in loco são muitas vezes consideradas eventos sagrados, uma vez que é nelas que o jogar acontece. Isso orienta duas condições que contribuem para esta digressão metodológica: (1) que a prática do jogo convoca um comportamento de respeito pelo fair play - uma trégua, ainda que sutil -, uma vez que (2) os comportamentos combativos são frequentemente demonstrados nas comunidades de suporte.

A pesquisa que dá sustento à observação empreendida neste artigo data do ano de 2016 e possui interlocutores e observações em vários estados do país, os quais pudemos visitar e acompanhar, ainda que brevemente, em grupos como os descritos acima. Nessa iteração, apresentamos uma compilação de eventos
${ }^{26}$ Evoque-se, uma vez mais, o conceito de tecnoculturas tóxicas, de Massanari (2017), que transparece com igual hostilidade nessas redes de comunicação on-line percebidas como espaços seguros (Braithwaite, 2016; Gray, 2014) para disseminação e prosperidade de discursos, práticas e comunidades com teor extremista e ultraconservador.

${ }^{27}$ Mortensen (2018) sublinha a dimensão desta persistência e continuidade ao discutir o Gamergate e seu uso desses espaços como "câmaras de eco" que promovem ódio e comportamentos violentos. Uma abordagem similar é oferecida por Braithwaite (2016). 
${ }^{28}$ Os nomes dos estabelecimentos foram omitidos para não expor os envolvidos nos casos apresentados nesta discussão. observados em lojas no Nordeste do Brasil - uma localizada em João Pessoa, capital da Paraíba, e outra em Teresina, capital do Piauí -, cuja documentação aconteceu presencialmente ao longo dos anos de 2017 e 2018, bem como a partir dos suportes digitais elencados anteriormente.

Como se pode inferir a partir desse delineamento, subsiste nessa aproximação uma compreensão das localizações geográficas destes espaços: é necessário perceber que o que está em jogo não é apenas o sujeito jogador de Magic, mas também a dimensão identitária encenada a partir do pertencimento a esses estados em particular ou, de forma mais geral, à região Nordeste. As visitas às lojas deram-se sempre uma ou mais vezes por semana, com incursões que duravam de uma a quatro horas diárias, às vezes no intuito de engajar no ambiente competitivo, outras simplesmente para adentrar a conversação e observar o trânsito de jogadores e da comunidade como um todo. No total contabilizamos mais de 500 horas de observação participante local e milhares de linhas de chats do WhatsApp.

O episódio narrado a seguir foi escolhido por envolver, particularmente, a presença do gênero feminino no ambiente, em uma dimensão tanto discursiva quanto presencial. Sublinhe-se que no aplicativo WhatsApp ou em iterações competitivas in loco, a presença de mulheres é rara. Nosso objetivo, por fim, é problematizar a forma a partir da qual as manifestações dessa masculinidade nerd/gamer tóxica ocorre nesses ambientes, a partir dessa ocorrência particular.

O cenário dos espaços dedicados a Magic é, no geral, heterogêneo: cada uma das lojas, como são comumente chamadas numa alusão ao inglês LGS, tem seus próprios parâmetros. Todas, contudo, são organizadas a partir de uma série de mesas com cadeiras em posições opostas, como se veria em um campeonato de xadrez. Sobre a mesa os jogadores estendem seus playmats - tapetes emborrachados que servem para que o contato com as mesas não danifique as cartas - $\mathrm{e}$ jogam suas partidas, que variam entre os formatos do jogo.

Foi num desses espaços, em João Pessoa ${ }^{28}$, que nos deparamos com um desenrolar interessante: quatro jovens em torno dos 20 anos jogavam com um produto selado, que funciona como um jogo de tabuleiro: já se sabe que cartas e que tipo de jogo ele produz. Estes produtos são comumente consumidos por jogadores casuais e colecionadores interessados não no aspecto competitivo do jogo, mas em seu aspecto temático/narrativo e material.

Enquanto observávamos o ambiente, percebemos que o tema do diálogo do grupo era a narrativa do jogo. Um dos jovens explicava para o grupo a relação entre Jace Beleren, arquetipicamente herói, e o vilão Nicol Bolas, personagens do multiverso de $M t G$. Em certo ponto da conversa, um comentário sobre o interesse romântico de Beleren, Liliana Vess, rapidamente se transformou em 
um debate acerca da esparsa presença de mulheres nas lojas de Magic. Esta questão é importante e diz respeito não apenas a processos de subjetivação e da encenação de uma masculinidade tóxica, mas também de como esses ambientes são constituídos para compreender esses espaços: por mais que muitas vezes sejam projetados como locais de socialização e performance a partir do consumo para a cultura nerd, o contingente de público feminino que os frequenta é sumariamente reduzido.

Este fato tanto convoca uma percepção da construção das identidades masculinas com relação à sua toxicidade (Chandler, 2019; Kupers, 2005), como colabora para que tais espaços contribuam para a dimensão do autorreforço. Cria-se o que Mortensen (2018) denomina de "câmaras de eco"29 (p. 791), que preconizam uma homogeneidade discursiva, ou aquilo que Gray (2014) chama de "um espaço 'seguro' para discutir e consumir ideias estereotipadas sobre raça e gênero" ${ }^{30}$ (p. xiii). Um dos estabelecimentos observados, em particular, agregava uma série de funções: ele era, sim, um espaço para a prática de Magic, mas também era uma lanchonete temática, com board games disponíveis para o público consumidor. Este espaço - muito mais que o primeiro - era bastante frequentado por mulheres, mas elas muito raramente desenvolviam qualquer relação com Magic. Era como se esta loja comportasse dois universos distintos no mesmo espaço comunal: em um deles, as pessoas comiam, bebiam e se divertiam; no outro, a energia era pesada e o conflito era palpável.

Retornando à conversa de nossos quatro rapazes, no momento em que o tema foi levantado, um deles tomou a palavra e começou a comentar um evento midiático ocorrido havia pouco tempo: no programa Encontro, apresentado por Fátima Bernardes e transmitido matinalmente pela Rede Globo, a atriz e youtuber Kéfera Buchmann corrigira abruptamente um jovem em rede nacional, utilizando termos como manterrupting e mansplaining em seu discurso (Nascimento, 2018). A mera lembrança do episódio foi o suficiente para exaltar um dos rapazes: "Ela interrompe o cara e vem falar de 'manterruption' [sic]!" - a última palavra com uma inflexão jocosa.

Chamou nossa atenção que aquela conversa aparecesse na discussão sobre a ausência feminina no jogo. Sua ocorrência implicava um conhecimento, por parte do grupo, de pautas multiculturalistas associadas ao feminismo, tema geralmente ignorado em círculos como esse (Gray, 2014; Murray, 2018; Salter, 2018; Salter \& Blodgett, 2017). Ignorado ou negligenciado não porque qualquer índice de comportamento tóxico ou misógino seja cerceado, mas simplesmente porque, pela natureza do espaço, o assunto simplesmente não vem à tona. A masculinidade desenvolvida e encenada em um ambiente como o dessas lojas é raramente confrontada, uma vez que a presença feminina se concentra quase
${ }^{29}$ No original: "echo chambers".

${ }^{30}$ No original: "'safe' space to discuss and consume stereotypical ideas about race and gender". 
sempre no nível de serviço. Todas as lojas que frequentamos tinham empregadas mulheres - caixas, serviços gerais, administradoras -, mas essas não participam da vivência da comunidade, sendo praticamente invisíveis no espaço de jogo.

$\mathrm{O}$ trânsito feminino nas mesas de jogo, esse sim é diminuto. Nos dois estabelecimentos que acompanhamos, apenas uma mulher se interessava por Magic e, mesmo assim, de forma casual por receio de adentrar o competitivo.

Meu motivo de não jogar competitivamente é que eu tenho transtorno de ansiedade, as competições me deixam ansiosa por causa do tempo limitado e como eu não sei jogar direito, eu preciso pensar muito nas jogadas e ter um tempo limitado me deixa nervosa ... eu achava intimidador pq [sic] eu tava [sic] começando no Magic e na loja só tinha jogadores experientes. Alguns eram legais comigo, tinham paciência pra [sic] responder uma dúvida ou me indicar um deck, mas no geral os jogadores são pouco receptivos. (Jogadora, 2019)

O relato é consonante com nossa observação porque tanto problematiza a forma como a figura da mulher é recebida no ambiente competitivo, inerente a esses estabelecimentos, quanto sublinha um design particularmente discriminatório no jogo. Magic possui um conjunto de regras extenso e complexo - mais de cem páginas em seu manual - e dominá-las é uma atividade que consome muito tempo. Para além deste tempo, aplicar as regras on the fly - na hora necessária - não é a mesma coisa que conhecê-las, o que significa que o jogo demanda muita atenção. Esse depoimento revela uma dimensão perniciosa do agôn, de Caillois (1958/2001): estes espaços de competição parecem promover uma hostilidade inerente na qual o reconhecimento pelos pares advém tanto do domínio dos aspectos técnicos do jogo quanto do compartilhamento de certos valores de uma determinada política identitária.

Este background é interessante porque contextualiza o problema levantado: como a loja de João Pessoa - diferentemente da outra com a qual tivemos um contato sistemático - é híbrida, funcionando também como lanchonete/board game store, o público que a frequenta é mais diverso do que nas outras instâncias. Sua estrutura é, também, consideravelmente superior, uma vez que ela precisa atender a outras expectativas de consumo. Assim, voltando para a condição na qual o diálogo se desenrolava, percebia-se que aquele espaço específico dava vazão a opiniões adversas que não seriam necessariamente debatidas em outro círculo. Uma narrativa indisputada na qual só se permite um certo tipo de ator.

O cenário se modifica, uma vez que outras pessoas adentram a loja: jovens mulheres que conhecem nossos atores vão até eles e os cumprimentam, mas se sentam em outra mesa e prosseguem para fazer pedidos e escolher um board 
game para passar o tempo. Para os jogadores de Magic, a conversa toma outro rumo, uma vez que seu espaço de performance de masculinidade e da crítica a ideias de cunho feminista se encontrava maculado pela presença feminina.

Discussões semelhantes foram presenciadas nos outros espaços sem que tivessem que ser necessariamente provocadas, mas dificilmente elas se encerram com um argumento que não seja conservador ou machista: a culpa das mulheres não jogarem Magic competitivo tem pouco a ver com os espaços serem comumente impenetráveis e necessariamente tóxicos, a culpa é delas, que simplesmente não querem jogar. Já nossa interlocutora reluta - "talvez o ambiente masculino assuste um pouco" (Jogadora, 2019) -, quando questionada acerca de amigas e conhecidas que se interessam pelo jogo, mas não pela LGS.

Gray (2014) defende que os jogos, assim como parte significativa da cultura pop, oferecem um espaço seguro que tanto atua como um meio para circulação de estereótipos aceitos do outro, quanto cria ambientes para normalizar essas representações e disciplinar todos os diferentes que procuram desafiar a organização hegemônica da cultura do jogo. Dito de outra forma, os jogos também representam a disseminação de piadas e preconceitos antes privados, mas agora frequentemente tornados públicos durante partidas de jogos e por diversas plataformas de streaming e serviços de redes sociais. Como dito, a comunidade nerd/gamer não concebe esses comentários como necessariamente públicos, uma vez que consideram os espaços de jogo - e mesmo os circundantes a ele - como se fossem de natureza privada. Esses índices são visíveis nos diálogos testemunhados na LGS de João Pessoa, ainda que não limitados a ela.

A noção de boyhood, de Burrill (2008), é muito proveitosa para que possamos compreender as condições discutidas anteriormente, uma vez que ela sugere uma manutenção espacial que garante a ausência da figura feminina. Sob o pretexto de falta de vontade desta, desenha-se um espaço de performance que oferece segurança e fomento para discursos de cunho machista, misógino e (ultra) conservador. Não obstante esta condição, nossa hipótese sublinha o fato de que tal ocorrência está ligada, sim, à forma como a cultura nerd se desenvolveu ao longo dos anos, mas também à forma - em seu sentido mais estrito - do jogo. Retornando à discussão sobre o design e a distribuição de Magic, podemos nos aproximar do problema da valoração de certas cartas e suas combinações e a partir disso inferir públicos-alvo e comportamentos.

Kendall (1999) aponta que o marcador de masculinidade hegemônica que perpassa o estereótipo nerd é o do alto poder aquisitivo e empregabilidade. Diferentemente de jogos que preservam o equilíbrio em sua experiência, em Magic os jogadores com maior poder aquisitivo são beneficiados pelo design do jogo, $o$ que implica em uma demografia predominante composta por homens brancos, 
${ }^{31}$ Essa estratificação percebida no próprio design do jogo é sujeita a variações por causa da multiplicidade de formatos adotada por Magic. O Pauper, por exemplo, que consiste apenas de cartas de raridade comum - ou seja, que ocorrem em número significativamente maior, aumentando sua oferta -, é um formato mais barato, com decks precificados na casa dos 50 dólares, segundo o site MTG Goldfish (https://bit.ly/3h4SS43). Contudo, não é adotado para competições oficiais, sendo considerado por muitos jogadores como um formato introdutório, para jogadores iniciantes ou para os que não têm como realmente investir no jogo. A própria existência do Pauper sublinha o caráter exclusivista de Magic.

${ }^{32}$ No original: "the specific dimensions of racism that serve to elevate white people over people of color". cis-heterossexuais e com poder aquisitivo acima da média. Estarem no topo de uma hierarquia cis-heteronormativa faz com que eles, além de ignorarem os privilégios imbricados em sua situação social, tornem-se extremamente protecionistas acerca de práticas assumidas por eles como exclusivamente masculinas ${ }^{31}$.

Para além do caso relatado, nossa experiência com o Magic competitivo nos apresentou uma atmosfera que variava de passivo-agressiva a hostil - raramente amistosa -, que demonstrava claramente a formação e a manutenção de grupos rivais sustentada pelo estímulo agonístico da premiação e do capital simbólico inerentes à vitória (Simmel, 1983). Nesse sentido, vale a pena sublinhar que os grupos de WhatsApp não se mostram muito diferentes do convívio pessoal nas lojas, no que diz respeito à hostilidade e a ausência feminina. Da mesma forma que se desenha um apagamento dessa presença em comunidades relacionadas à cultura nerd, produzido pela encenação de uma boyhood (Burrill, 2008) que eclipsa a subjetividade feminina nesses âmbitos, haveria de se esperar que o mesmo acontecesse em contextos digitais, como os grupos de WhatsApp que servem de suporte às lojas - afinal, como dito por Braithwaite (2016), as mídias sociais também operam como espaços seguros para a propagação da misoginia agressiva e violenta. É o que de fato nossa observação sugere, uma vez que em espaços exclusivamente masculinos atitudes violentas e temas como pornografia são comumente presentes e colaboram para a condição.

As relações entre as formas de interdição, disciplinamentos e policiamentos de identidade promovidas no âmbito de Magic não apresentam uma coincidência residual com a campanha Gamergate, mas estão alinhadas a um longínquo processo de subjetivação da masculinidade nerd tóxica que está sempre à disposição. A reincidência desse conjunto de ansiedades, estratégias retóricas e campanhas de ódio direcionadas às mulheres e minorias étnico-raciais pode ser e será sempre que necessário - acionado para subalternizar a presença feminina, ou de outras minorias, em um espaço cultural e historicamente construído sob o domínio e para perpetuação do poder masculino.

A busca por legitimidade e igualdade de direitos pelas minorias fere, assim, o princípio básico do imaginário presente em parte considerável da demografia de jogadores e nerds: uma sociedade construída sob o alicerce de uma falsa meritocracia que esconde séculos de dívidas sociais e étnico-raciais. Este argumento, seguido pelo debate sobre a estratificação de classe promovida pelo design de $M t G$, é relevante, pois a comunidade de jogadores não somente é marcada pela masculinidade e oposição às feminilidades, mas também pela branquitude, "as dimensões específicas do racismo que servem para elevar os brancos sobre os negros"32 (DiAngelo, 2011, p. 56). DiAngelo (2011) argumenta que os brancos da América do Norte vivem em um ambiente social responsável 
por resguardá-los e isolá-los do estresse racial - resultante de uma interrupção do que é considerado racialmente familiar, segundo a autora. Esses ambientes isolados de proteção hierárquica racial, que espaços (e situações) de jogo podem com relativa facilidade encenar, produzem expectativas brancas para o conforto racial na medida em que, simultaneamente, limitam a capacidade de tolerar $o$ estresse racial - e, acrescentemos, de gênero e classe. A ruptura dessa proteção desencadeia o que o autor chama de fragilidade branca.

A fragilidade branca é um dos aspectos da branquidade e seus efeitos. É um estado alimentado por situações de estresse racial, responsável por invocar uma série de movimentos defensivos, alguns dos quais abrangem a externalização de emoções como raiva, mágoa, medo e culpa, além de comportamentos como argumentação, silêncio e o abandono de uma determinada situação que incita o estresse. Essas condutas cumprem a função de restabelecer o equilíbrio racial dos brancos. Essas interrupções, de acordo com DiAngelo (2011), têm a capacidade de assumir uma multiplicidade de formas e advir de um número considerável de fontes (p. 57).

Os discursos e comportamentos observados nos permitem inferir que os movimentos das minorias em busca de visibilidade são sintomas de uma condição do que podemos chamar de fragilidade do jogador e esta, por sua vez, compõe parte essencial do estabelecimento de estruturas normativas e tóxicas em ação no âmbito de $M t G$. Essas estruturas condicionam e conferem o estatuto de interdito a todas as minorias em disputa na batalha contemporânea pela renegociação da identidade gamer. A ideia de fragilidade do jogador, em uma alusão velada à fragilidade branca (DiAngelo, 2011), da qual - por razões óbvias - se alimenta, pode ser adequadamente ilustrada pela noção de boyhood, de Burrill (2008), e compreendida como um conjunto de reações defensivas. Trata-se de um estado no qual mesmo a mínima quantidade de estresse desencadeado por ações equitativas de gênero, étnico-raciais, classista ou sexualidade tornam-se inaceitáveis, ocasionando uma variedade de movimentos defensivos, disciplinamentos e policiamentos que culminam na manifestação de formas diversas de masculinidade tóxica e tecnoculturas tóxicas - incluindo múltiplas práticas de violência.

O conjunto desses movimentos, de maneira similar à fragilidade branca definida por DiAngelo (2011), incorpora a manifestação externa de emoções como raiva, mágoa e medo, além de comportamentos agressivos de natureza diversa. Essas condutas, por sua vez, têm a função de restaurar o jogo como um passatempo masculino inócuo, um espaço de conforto branco, e o equilíbrio e hierarquia étnico-racial, de gênero e de classe dos jogadores brancos cis-heterossexuais, de uma pretensa e nostálgica identidade gamer original, de 
${ }^{33}$ No original: "The 2014 online hate-storm presaged the tactics of the Trump-loving far right movement".

${ }^{34}$ No original: "Leading up to the Charlottesville rallies, alt-right organizers used a messaging service called Discord, originally created for video gamers. This is the latest in the history between the alt-right and the gaming community". uma narrativa responsável pela construção de uma visão de mundo na qual os jovens brancos, alheios às definições tradicionais de masculinidades, são heróis transformados em vítimas pelo contínuo avanço de uma agenda a favor da diversidade e do multiculturalismo.

Assim, as manifestações de masculinidade tóxica contra mulheres e outras minorias na cultura gamer podem ser interpretadas como uma tentativa de manter o espaço dos homens brancos nerds incólume. Esse mecanismo de defesa reafirma uma rejeição à hipermasculinidade física tradicional, ao passo que constitui outro tipo de fraternidade que oferece um espaço alternativo de encenação centrado em uma performance de racionalidade e positivismo.

Em 2016, após as eleições para a presidência nos Estados Unidos, o Gamergate ressurgiu no discurso popular (Salter \& Blodgett, 2017). As semelhanças do Gamergate e das manifestações de masculinidade tóxica de jogadores de Magic - ainda que não restritas apenas a estes - com o movimento on-line de extrema direita, o alt-right - e deste com o bolsonarismo e o trumpismo -, são diversas e de maneira alguma devem ser lidas como mera casualidade. Essas relações são reforçadas na videorreportagem How Gamers Are Facilitating the Rise of the AltRight, da NBC News (2017), e na análise de Lees (2016) sobre a conexão entre o Gamergate, as relações com a Casa Branca e o quanto "a tempestade de ódio on-line de 2014 pressagiou as táticas do movimento de extrema direita que ama Trump"33 (para. 1). "Antes dos comícios em Charlottesville, os organizadores da alt-right usaram um serviço de mensagens chamado Discord, originalmente criado para jogadores de videogame. Este é o mais recente na história entre o alt-right e a comunidade de jogos" ${ }^{34}$ (NBC News, 2017, para. 1).

Esses relatos demonstram que esses vínculos são mais densos do que se imagina: há uma estreita relação entre o discurso da exclusão e da subalternização empregado por jogadores e nerds e o promovido pela chamada mídia alt-right, que se assenta em comunidades existentes, a exemplo dos ativistas dos Direitos dos Homens, e uma variedade de outros movimentos direcionados a homens que creem que o passado lhes proporcionou mais proveitos e privilégios do que o atual presente. Nosso argumento, em consonância com as análises de Lees (2016) e Salter e Blodgett (2017), é que o etos nostálgico e o (ultra)conservadorismo sustentam tanto o conjunto de estratégias retóricas e campanhas de ódio empregado no Gamergate quanto a encenação centrada em uma performance das masculinidades (tóxicas) por jogadores de Magic e, mais que isso, podem ser lidos como índices intrínsecos de uma vinculação ao alt-right.

A despeito do aglomerado de dinâmicas exibidas em Magic e no Gamergate, em última instância, ser nutrido pela vingança de homens contra mulheres, produziu-se uma narrativa particular de reforma: um apelo para tornar os jogos 
grandes novamente - cuja semelhança com o slogan da campanha eleitoral adotada por Donald Trump em 2016 (Make America Great Again) não é mera coincidência. $\mathrm{O}$ movimento desenvolvido continuamente na comunidade de prática de $M t G$ não deve ser concebido como um caso isolado de um contexto pregresso, mas como parte de uma campanha histórica de resistência à marcha democrática empreendida pela reunião de mulheres e minorias sociais em posições subalternizadas contra seus opressores no estado, no local de trabalho, na igreja e em outras instituições hierárquicas desde o início da chamada "Era Moderna" (Robin, 2011).

Esse contexto não se desvincula das diversas manifestações do entretenimento do nosso tempo, seja nos esportes, seja nos video games, como reforçam as análises de Falcão, Marques, Mussa e Macedo (2020), Lees (2016) e NBC News (2017). Em quase todas as campanhas, sob bandeiras variadas - movimento trabalhista, feminismo, abolição, descolonização, sexualidade, socialismo - e slogans diferentes - liberdade, igualdade, direitos, democracia, revolução -, essa resistência ocorreu com violência e não violência, aberta e secretamente, legal e ilegalmente (Robin, 2011). Nosso argumento é colocar tanto as marchas quanto as contramarchas em $M t G$ como parte da história da política contemporânea, ou pelo menos como uma de suas histórias. São batalhas entre grupos sociais; entre aqueles que detêm mais poder e aqueles que lutam por mudanças em espaços historicamente colonizados.

\section{CONSIDERAÇÕES FINAIS: O QUE ESTÁ EM JOGO?}

Neste artigo, buscamos relacionar os efeitos da criação e performance de uma masculinidade tóxica à experiência da comunidade de prática de $M t G$. Nas lojas observadas, a presença de jogadoras é ainda bastante limitada e as discussões sequer chegam à esfera do silenciamento, pois o acesso ao jogo é dificultado. De um cerceamento menos hostil a manifestações de jogadores homens contra a presença feminina em seus espaços, o que se percebe é a produção de uma masculinidade que se faz não a partir da diferença, mas em detrimento dela: o fomento de um ambiente de homogeneidade que garante que o espaço gerado em lojas e grupos de WhatsApp seja considerado seguro para manifestação de ideias violentas e exclusão do que é feminino. A identificação dos jogadores e donos de loja, contrários à presença feminina no $M t G$, com a figura de Jair Bolsonaro e com simbologias e discursos adotados pela extrema direita e pelo ultraconservadorismo também apontam o desejo pela manutenção do privilégio masculino e da identidade nerd e gamer como foi concebida e consolidada. 
Nossa análise sugere que as manifestações de masculinidades tóxicas em $M t G$, enquanto modos de práticas conservadoras (Robin, 2011) e conjunto de formas de reações defensivas (DiAngelo, 2011), são reativas, contingentes e complementares a um programa político radical antagônico defendido por mulheres e minorias sociais - sem o qual essas ações perdem força e potência retórica. As ideias políticas de parte considerável da demografia de jogadores, que geralmente ocupam o lado direito do espectro político e se pretendem apolíticas, são forjadas em batalha, em um intenso campo de lutas demarcado por fronteiras reais e retóricas (Salter \& Blodgett, 2017). Diferentemente do que sugere Robin (2011), contudo, o conservadorismo às avessas - ou melhor, o ultraconservadorismo - em $M t G$ permanece na defesa irrefletida de um antigo regime imutável ou de um tradicionalismo pensativo objeto de idolatria.

Assume, assim, uma postura reacionária ao mostrar uma insistente inclinação a recriar uma certa idealização do passado, fundamentada em uma suposta era dourada, que contém, em sua epistemologia, traços ideacionais e transcendentes - típicos das ideologias não conservadoras - que vão de encontro à natureza imanente do conservadorismo (Trigueiro, 2015). Podemos chamá-la de ultraconservadorismo. O processo de subjetivação da masculinidade tóxica se dá, em parte, por uma encenação da violência enquanto dispositivo disponível a esses jogadores para policiamento de identidade. Aqui a variedade de manifestações da fragilidade do jogador, que muitas vezes irrompe quando brancos são desafiados em suas visões de mundo racial, ilustra a função de restabelecer o equilíbrio e hierarquia étnico-racial, de gênero e classista dos jogadores brancos cis-heterossexuais. Estudos futuros devem ajudar no mapeamento das múltiplas formas - abrangendo várias práticas de violência - $\mathrm{e}$ fontes pelas quais atuam a fragilidade do jogador e a masculinidade tóxica, incluindo diferentes atividades e situações de jogo.

Por fim, este artigo é uma primeira incursão que aponta para a necessidade de exploração desses ambientes como espaços de performance da cultura política, conectando, assim, comportamentos e discursos observados não apenas com performances políticas particulares da cultura brasileira - no caso de uma relação entre jogadores de $M t G$ e apoiadores do presidente Jair Bolsonaro -, mas, sobretudo, subjetividades desenvolvidas a partir da percepção das indústrias criativas como parte do ecossistema do capitalismo neoliberal e dos processos de colonização pelos quais o Brasil passou. Além disso, traços revelados não só nos discursos explicitados neste artigo, mas em outros aspectos de nossa amostragem, sugerem uma ligação desse discurso conservador e tradicionalista (patriarcal) com outros de cunho neofascista. Esforços posteriores devem explorar esta via, que parece convergir para a identidade do público consumidor de Magic no Brasil. M 


\section{REFERÊNCIAS}

Ahmed, S. (2010). The promise of happiness. Duke University Press.

Braithwaite, A. (2016). It's about ethics in games journalism? Gamergaters and geek masculinity. Social Media + Society, 2(4), 1-10. https://doi. org/10.1177/2056305116672484

Burrill, D. (2008). Die tryin': Videogames, masculinity, culture. Peter Lang.

Caillois, R. (2001). Man, play and games. University of Illinois Press. (Trabalho original publicado em 1958)

Chandler, A. (2019). Gamers speak: Analyzing masculine speech in gaming culture. CLA Journal, 7(1), 11-34. https://bit.ly/3woztzq

Chase, E. (2018, 6 de dezembro). The next chapter for Magic: Esports. Magic: The Gathering. https://bit.ly/3w64nwC

Connell, R. (1993). The big picture: Masculinities in recent World History. Theory and Society, 22(5), 597-623. https://doi.org/10.1007/BF00993538

Connell, R. (2001). The social organization of masculinity. In S. Whitehead \& F. Barrett (Eds.), The masculinities reader (pp. 30-48). Polity.

Connell, R. (2005). Masculinities (2a ed.). Polity.

Connell, R., \& Messerschmidt, J. (2005). Hegemonic masculinity: Rethinking the concept. Gender \& Society, 19(6), 829-859. https://doi. org/10.1177/0891243205278639

Coontz, S. (2000). The way we never were: American families and the nostalgia trap. Basic Books.

DiAngelo, R. (2011). White fragility. The International Journal of Critical Pedagogy, 3(3), 54-70. https://bit.ly/3worQsM

Falcão, T. (2014). Não humanos em jogo: Agência e prescrição em World of Warcraft [Tese de doutorado, Universidade Federal da Bahia]. Repositório Institucional da UFBA. https://bit.ly/36M9ckk

Falcão, T., \& Marques, D. (2019). Pagando para vencer, parte 2: Serialização, power creep e capitalismo tardio em Hearthstone. Comunicação, Mídia e Consumo, 16(47), 530-554. http://dx.doi.org/10.18568/cmc.v16i47.1894

Falcão, T., Marques, D., \& Mussa, I. (2020). \#BoycottBlizzard: Capitalismo de plataforma e a colonização do jogo. Contracampo, 39(2), 59-78. http://doi. org/10.22409/contracampo.v0i0.38578

Falcão, T., Marques, D., Mussa, I., \& Macedo, T. (2020). At the edge of utopia. esports, neoliberalism and the gamer culture's descent into madness. gamevironments, 13, 382-419. https://doi.org/10.26092/elib/411

Fisher, M. (2009). Capitalist realism: Is there no alternative? Zero Books. Goffman, E. (1961). Encounters: Two studies in the sociology of interaction. Bobbs-Merrill. 
Gray, K. (2014). Race, gender, and deviance in Xbox Live: Theoretical perspectives from the virtual margins. Elsevier.

Griffith, E. (2020, 3 de agosto). Jund sacrifice. MTG Goldfish. https://bit. ly/3jr9NQb

Hjarvard, S. (2013). The mediatization of culture and society. Routledge.

Huizinga, J. (2001). Homo ludens: O jogo como elemento da cultura. Perspectiva. (Trabalho original publicado em 1938)

Johnson, R. (2018). Technomasculinity and its influence in video game production. In N. Taylor \& G. Voorhees (Eds.), Masculinities in play (pp. 249-262). Palgrave Macmillan.

Juul, J. (2005). Half-Real: Video games between real rules and fictional worlds. MIT Press.

Juul, J. (2010). A casual revolution: Reinventing video games and their players. MIT Press.

Kendall, L. (1999). Nerd nation: Images of nerds in US popular culture. International Journal of Cultural Studies, 2 (2), 260-283. https://doi. org/10.1177/136787799900200206

Kendall, L. (2000). "Oh no! I'm a nerd!": Hegemonic masculinity on an online forum. Gender \& Society, 14(2), 256-274. https://doi. org/10.1177/089124300014002003

Kupers, T. (2005). Toxic masculinity as a barrier to mental health treatment in prison. Journal of Clinical Psychology, 61(6), 713-724. https://doi.org/10.1002/ jclp.20105

Lane, K. (2018). How was the nerd or geek born? In K. Lane (Ed.), Age of the geek: Depictions of nerds and geeks in popular media (pp. 1-18). Palgrave Macmillan.

Latour, B. (1993). We have never been modern. Harvard University Press.

Lees, M. (2016, 1 de dezembro). What Gamergate should have taught us about the alt-right. The Guardian. https://bit.ly/3hoTZM4

Massanari, A. (2017). \#Gamergate and the fappening: How Reddit's algorithm, governance, and culture support toxic technocultures. New Media \& Society, 19(3), 329-346. https://doi.org/10.1177/1461444815608807

Morris-Lent, C. (2019, 15 de fevereiro). I won a \$5,000 Magic: The gathering tournament on shrooms. Gawker. https://bit.ly/3ypo1W4

Mortensen, T. (2018). Anger, fear, and games: The long event of \#Gamergate. Games and Culture, 13(8),787-806. https://doi.org/10.1177/1555412016640408

Murray, S. (2018). On video games: The visual politics of race, gender and space. I.B. Tauris. 
Nascimento, F. (Produtor executivo). (2018, 13 de dezembro). Encontro com Fátima Bernardes [Programa de televisão]. Globoplay. https://bit.ly/3jsYhUq NBC News. (2017, 30 de outubro). How gamers are facilitating the rise of the alt-right: Think: NBC News [Vídeo]. YouTube. https://bit.ly/3hoe1Xc

Oakeshott, M. (1991). Rationalism in politics and other essays. Liberty Fund.

Reeser, T. (2010). Masculinities in theory: An introduction. Wiley-Blackwell.

Robin, C. (2011). The reactionary mind: Conservatism from Edmund Burke to Sarah Palin. Oxford University Press.

Robinson, L. (2007). The cyberself: The self-ing project goes online, symbolic interaction in the digital age. New Media \& Society, 9(1), 93-110. https:// doi.org/10.1177/1461444807072216

Salter, M. (2018). From geek masculinity to Gamergate: The technological rationality of online abuse. Crime, Media, Culture: An International Journal, 14(2), 247-264. https://doi.org/10.1177/1741659017690893

Salter, A., \& Blodgett, B. (2017). Toxic geek masculinity in media: Sexism, trolling, and identity policing. Palgrave Macmillan.

Simmel, G. (1983). Georg Simmel: Sociologia. Ática.

Švelch, J. (2020). Mediatization of a card game: Magic: The Gathering, esports, and streaming. Media, Culture \& Society, 42(6), 838-856. https://doi. org/10.1177/0163443719876536

Torlay, B. (2020, 23 de janeiro). Por que as feminazis são infelizes? [Vídeo]. YouTube. https://bit.ly/2UHuInw

Trammel, A. (2020). Torture, play, and the black experience. G|a|m|e: The Italian Journal of Game Studies, (9), 33-49.

Trigueiro, G. (2015). Conservadorismo: Perspectivas conceituais. Revista Estudos Políticos, 6(11), 97-118.

West, C., \& Fenstermaker, S. (1995). Doing difference. Gender \& Society, 9(1), 8-37. https://doi.org/10.1177/089124395009001002

Wizards of the Coast. (2017, 13 de junho). How to play Magic: The Gathering [Vídeo]. YouTube. https://bit.ly/2UHuU6e

Zeranox. (2020, 12 de junho). Bant control. MTG Goldfish. https://bit.ly/3hgqyLb

Artigo recebido em 11 de setembro de 2020 e aprovado em 5 de junho de 2021. 